\title{
A FIELD STUDY TO TRACE THE MATERNAL IMMUNITY OF CHICKEN INFECTIOUS ANEMIA IN BROILER CHICKEN
}

\author{
KIFAH NASHAR* ${ }^{*}$ and ANOUAR ALOMAR ${ }^{* *}$ \\ ${ }^{*}$ Fact. of Vet. Med.-Albaath University. \\ *** Fact. of Vet. Med.-Albaath University. \\ Email: nasharvet@gmail.com
}

\section{ABSTRACT}

Received at: 7/8/2014

This study was applied on two broiler flocks. Chickens in the experiment were divided into two groups, the first group was generated from unvaccinated breeders, while the

Accepted: 16/11/2014 second one was generated from breeders which was vaccinated with attenuated live vaccine of CIA. Indirect ELISA test was applied in this study to observe the maternal immunity levels and its decrease in both groups. The results showed that the maternal immunity levels in the second group was higher than the levels in the first one. The CV\% which expresses the homogeneity of flock immunity levels was compared. It was found that the homogeneity in the second group was higher than that of the first one. The decrease rate of maternal immunity levels of CIA was compared in both groups. The results showed that it was higher in the first group. The results of this experiment showed the necessity of vaccination in breeders against CIA to produce good protected chicken with protective immunity levels.

Key words: Maternal immunity, Chicken infectious anemia, Broiler chicken.

\section{دراسة حقلية لتتبع مستويات المناعة الأمية في صيصان دجاج اللحم لمرض فقر الام المعدي في الاجاج

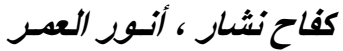 \\ Email: gfnasharvet@gmail.com}

أجريت هذه الدر اسة على قطيعي دجاج لحم ، حيث قيمت أفر اد التجربة إلى مجمو عتين ، المجمو عة الأولى صيصان دجاج لحم ناتجة

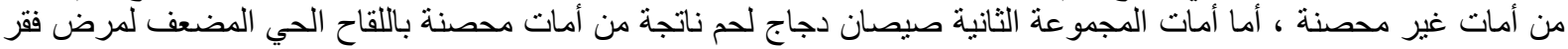
الدم المعدي.

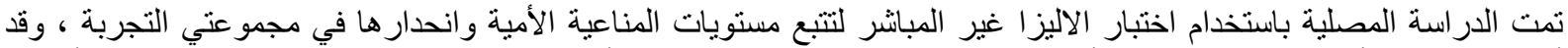

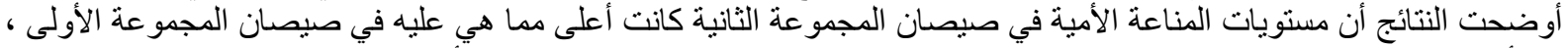

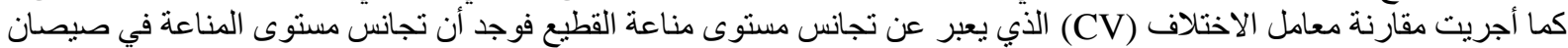

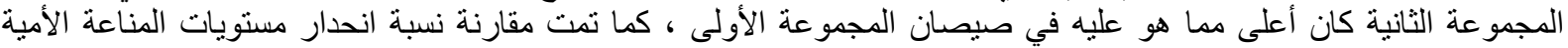

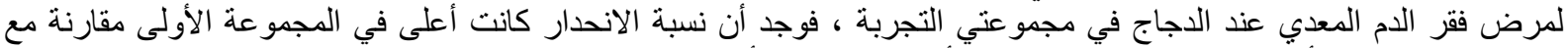

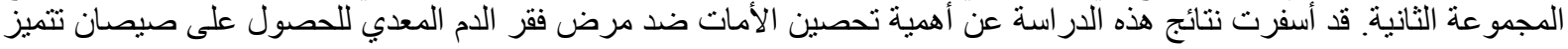

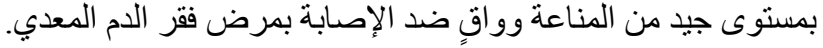

\section{INTRODUCTION}

\section{المقدمـة}

أفادت التقارير بوجود فيروس فقر الدم المعدي في قطعان الدجاج منذ عام • •و ام (Jakowski et al., 1970) ، ونم عزله لأول

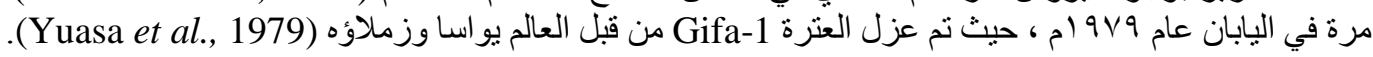

وفي عام بهو ام رصد يواسا وزملاؤه تكاثر الفيروس في خطوط خلوية محضرة من أرومات الخلايا اللمفاوية الاجاجية مسبباً تغير ات مرضية خلوية (Yuasa et al., 1983a) CPE).

وقد أثنارت تقارير مصلية عديدة إلى وجود المرض في معظم بلدان العالم التي تنتشر فيها نربية الدواجن، وقد عُزل الفئ الفيروس في كلٍ من اليابان و الصين و استر اليا ونيوزيلندا وجنوب إفريقيا (Roussan, 2006). وصُنفِ ضمن عائلة فيروسات سيركو Circoviridae) 
و التي تضم ثلاثة أجناس هي جنس سيركوفيروس circovirus الذي يضم نوعين هما سيركوفيروس الخنزيري، وسيركوفيروس

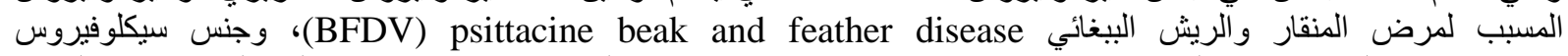
Cyclovirus الذي يصيب الحشرات، وجنس جيروفيروس Gyrovirus والذي يسبب مرض فقر الدم الدعدي عند الدجاج .(Mankertz, 2008)

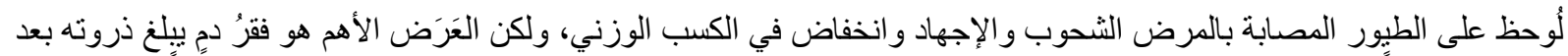

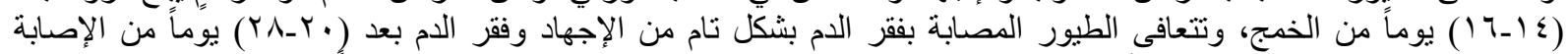

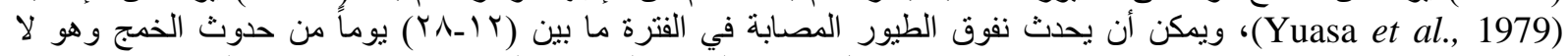

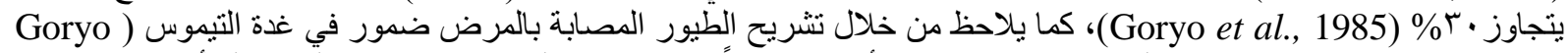
والون

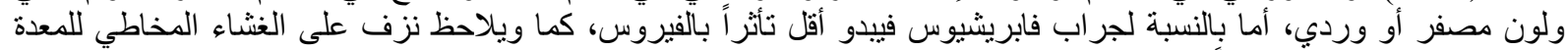

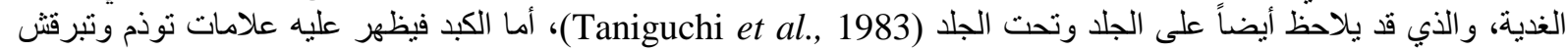

.(Goryo et al., 1989)

أما بالتشريح النسيجي المرضي فيلاحظ ضمور لمفاوي متعمم، حيث يسبب المرض كبناً مناعياً (Yuasa, 1983).

ينتقل المرض عامودياً و أفقياً (Yuasa et al., 1983b)، حيث يتم الانتقال العمودي للفيروس عن طريق بيض التفريخ الذي يعتبر الطريق الأكثر أهمية في انتقال العدوى (Chettle et al.,1989).

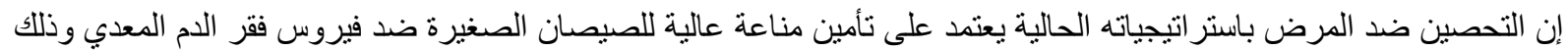

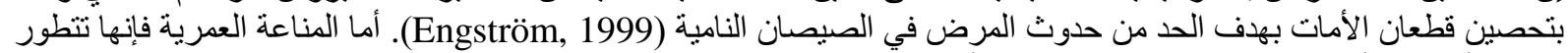
خلال الأسبوع الأول من العمر وتكتمل بعمر ثلاثة أسابيع (Yuasa and Imai,1986).

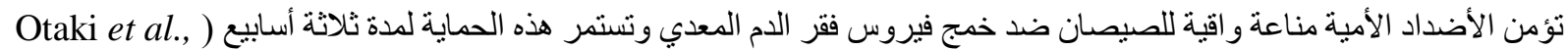

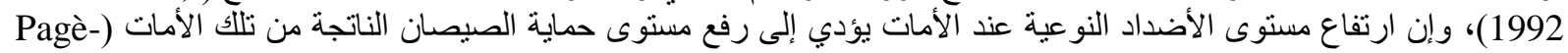

.(Manté et al., 1997

إن الأضداد المناعية الأمية ضد خمج فقر الدم المعدي تقي الصيصان بشكل فعال من المرض شريطة عدم وجود كبت مناعي من مسببات فيروسية أخرى مثل الخمج بمرض خدر التهاب الجر اب المعدي (Yuasa et al., 1980).

\section{MATERIALS and METHODS مواد وطرائق العمل}

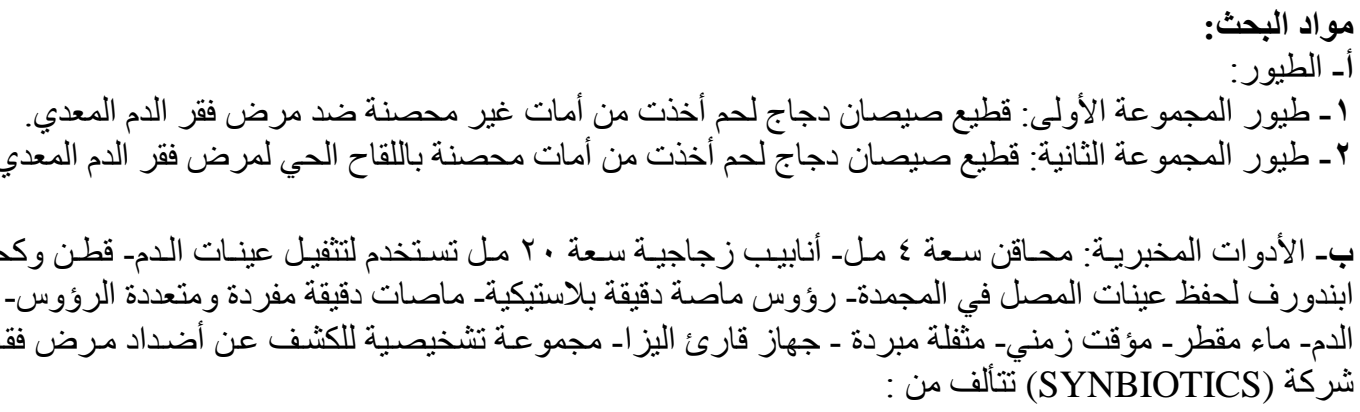

1 - خمسة أطباق 97 حفرة ثبت عليها مستضد خامل لفيروس فقر الدم المعدي Bufled plate.

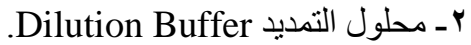
r r ـ محلول إيقاف التفاعل Stop Solution

ع ـ - محلول الغسيل Wash Solution

هـ الثاهد الإيجابي CAV Positive Control Serum.

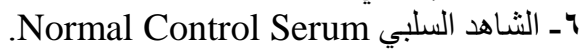

V- هحلول الركيزة اللونية ABTS-Hydrogen peroxide Substrate Solution

Aـ محلول الاقتران المرتبط بالأنزيم Goat anti-Chicken IgG (H+L) Peroxidase Conjugate Solution. 


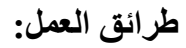

تمت تربية قطيعي التجربة في ظروف مشابهة للظروف الحقلية لمحاكاة الواقع الحقلي مع ملاحظة الأخذ بجميع احتياطات الأمن

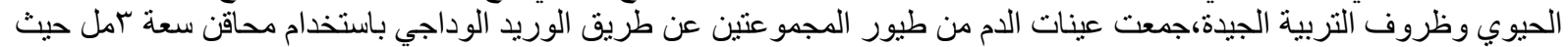

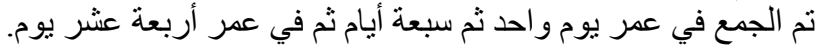

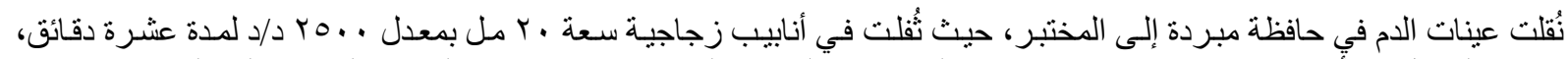

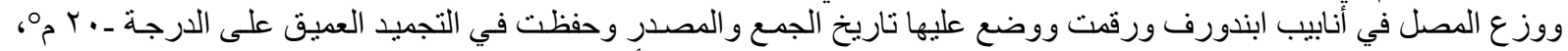

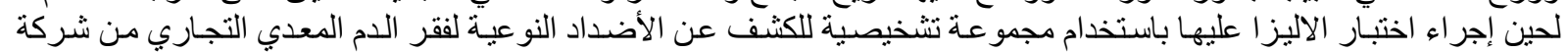

.(Synbiotic Corporation, USA)

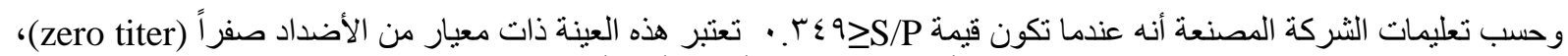

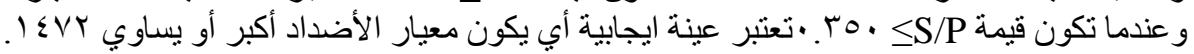

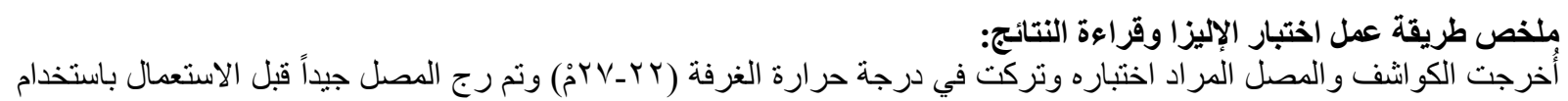
جهاز الرج الكرج

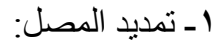

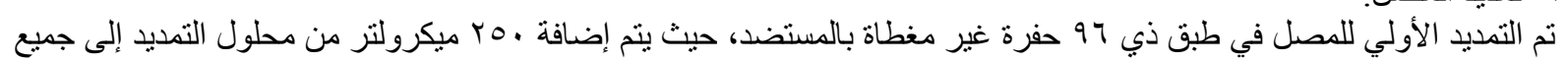

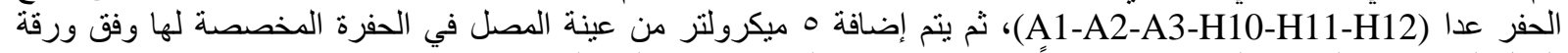

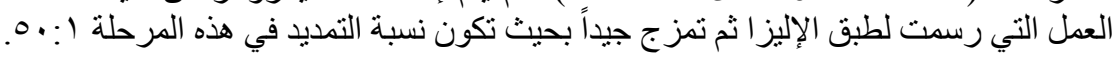

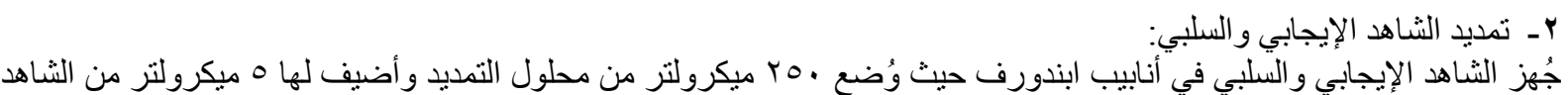

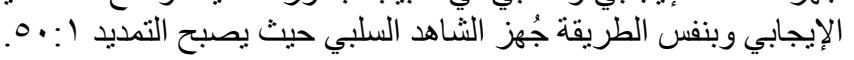

rـ تجهيز محلول الاقتر ان المرتبط بالأنزيم المقترن Conjugate

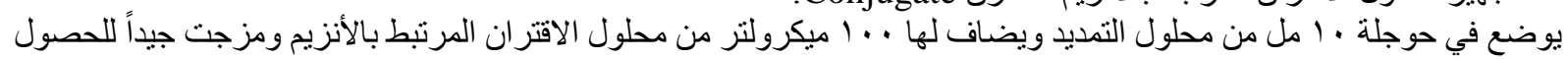

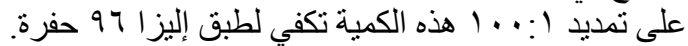

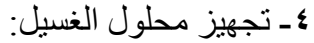

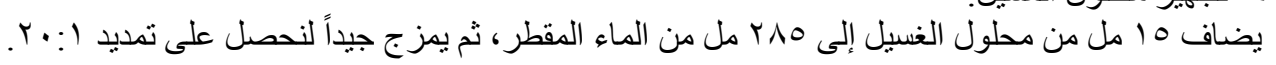

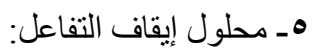

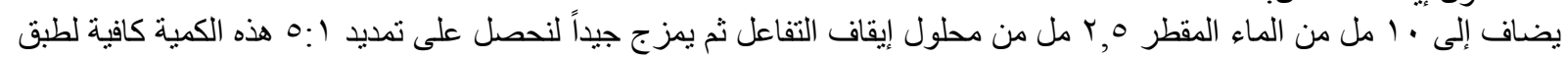

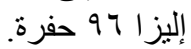
طريقة العمل: - - م

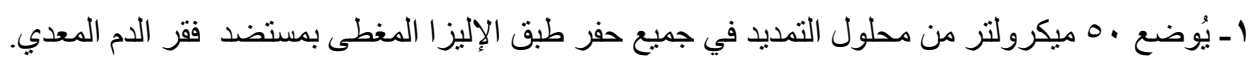

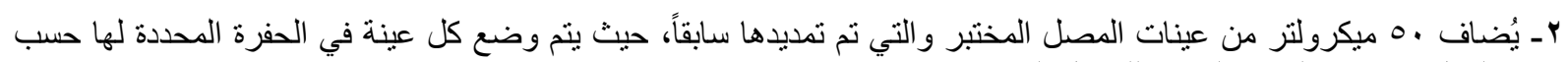

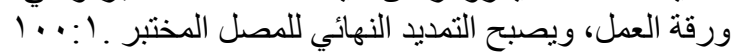

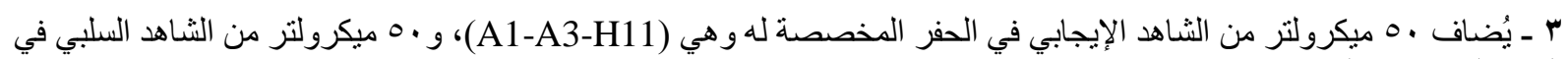
الحفر المخصصة له وهي (A2-H10-H12).

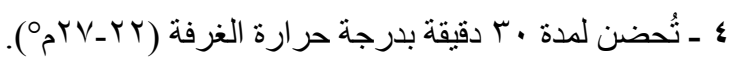

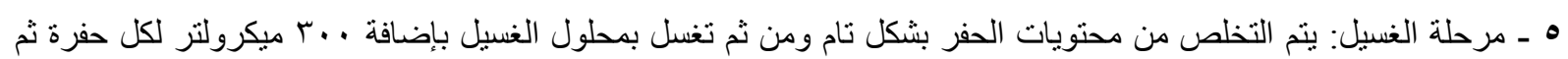

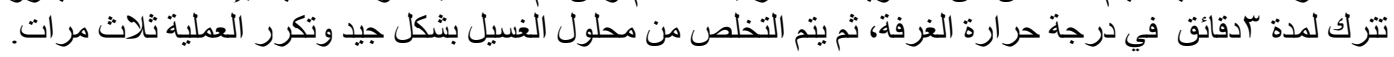

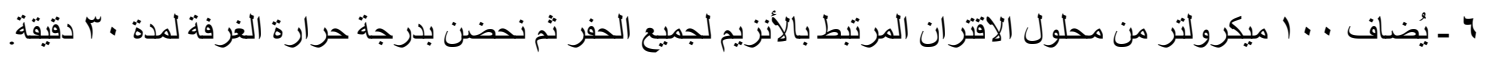

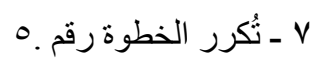

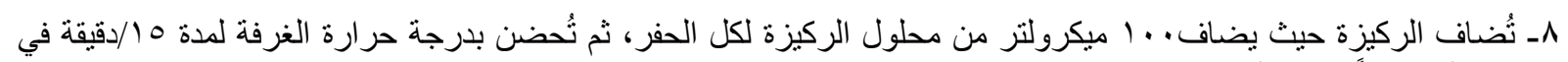
مكان مظلم مغطاةً بورق حبث القصدير. 9 ـ يُضاف . . 1 ميكرولتر من محلول إيقاف التفاعل مع الانتباه لعدم تشكيل فقاعات هو ائية.

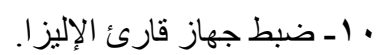




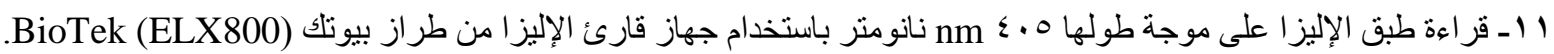

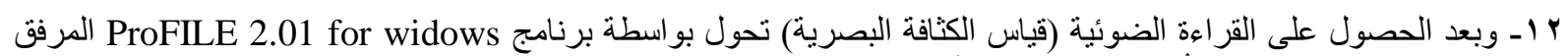

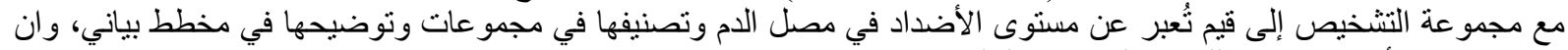
حساب عيار الأضداد يخضع اللعلاقة الرياضية التالية:

$\mathrm{S} / \mathrm{P}=($ Sample Abs -Average normal control Abs $) /$

\section{(corrected Positi $\square$ e control Abs)}

$\log 10$ Titre $=(1.009 x \log 10 \mathrm{~S} / \mathrm{P})+3.628$

Titre $=$ Antilog of Log10 Titre

\section{$\frac{\mathbf{S}}{\mathbf{P}}=\frac{(\text { Sample Abs }- \text { Average normal control Abs })}{\text { corrected Positive control Abs }}$}

يؤخذ بعين الاعتبار انه في الشروط الطبيعية للاختبار يجب أن تكون قيمة الكثافة البصرية للثاهد السلبي تتراوح بين ه •, •• إلى بلى

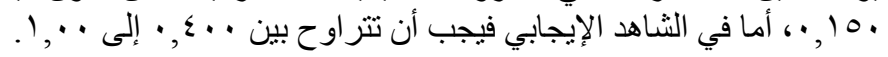

ويعتبر اختبار الإليزا لمعايرة الأضداد النوعية لفقر الدم المعدي عند الدجاج صحيحاً ومعتداً عندما تكون قيمة الكثافة البصرية للثاهد

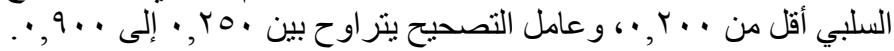

\section{RESULTS \\ النتأيـج}

اـ نتائج قياس الأضداد في المجمو عة الأولى (صيصان ناتجة من أمَّات غير محصنَّة):

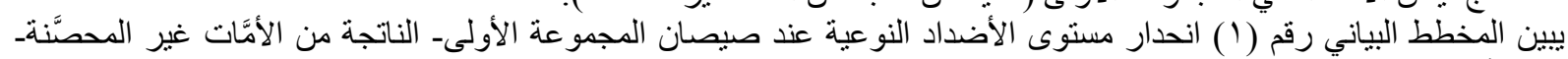

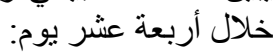

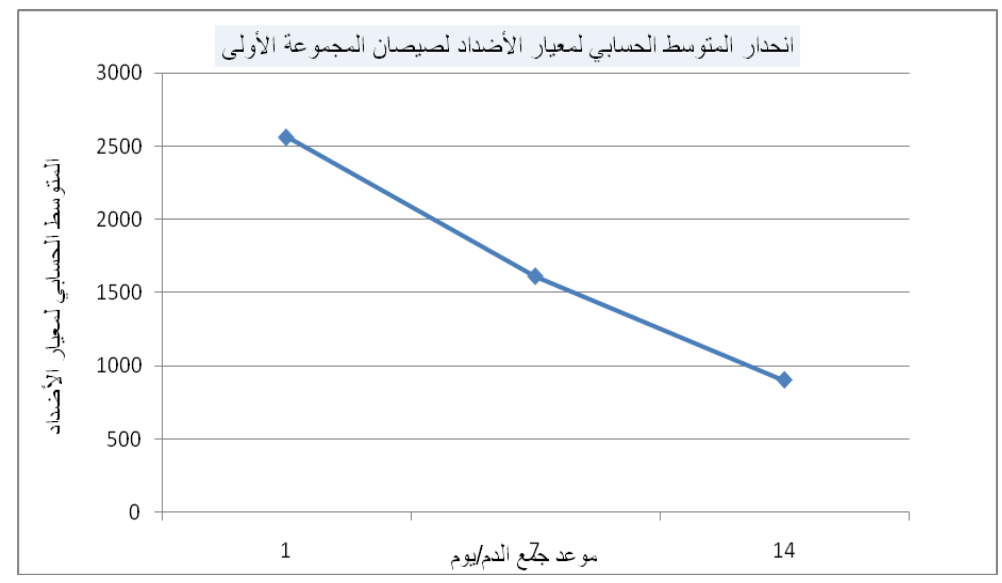

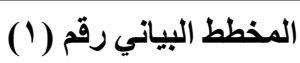

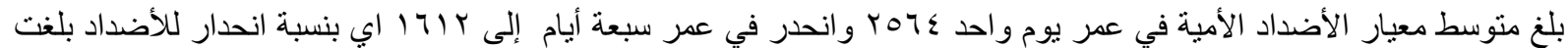

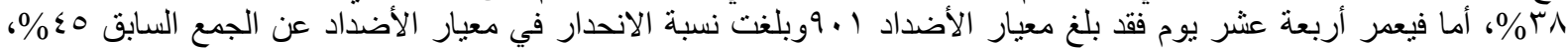

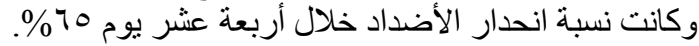

يظهر الجدول رقم 1: قيمة معامل الاختلاف والقيمة صفر ومقدار الانحدار الحاصل خلال ؟ ـ يوماً في صيصان المجموعة الأولى.

\begin{tabular}{|c|c|}
\hline 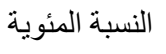 & 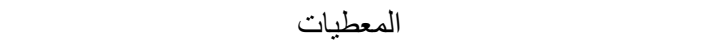 \\
\hline$\% \circ \vee, 0$ & معامل الاختلاف في عمر يوم CV\%. \\
\hline$\% 1 \leq$ & النسبة المئوية للعينات التي أعطت قيمة صفراً في عمر يوم واحد. \\
\hline$\% 70$ & النسبة المئوية لانحدار معيار الأضداد خلال ؛ (يوماً. \\
\hline
\end{tabular}


بـ نتائج قياس الأضداد في المجمو عة الثنانية (صيصان ناتجة من أمَّات محصَّنة):

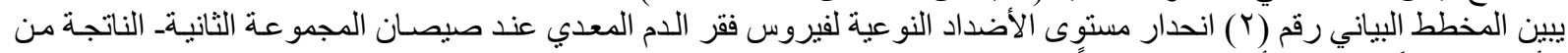
الأمَّات المحصَّنة ـ خلال أربعة عشر يوان.

\section{(r) (المخطط البياني رقم}

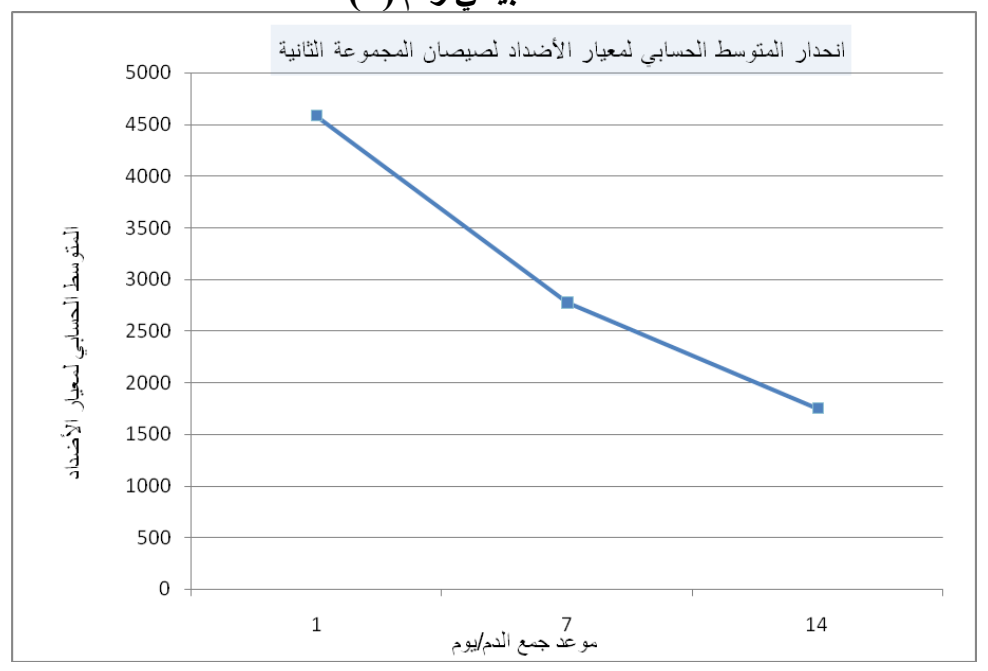

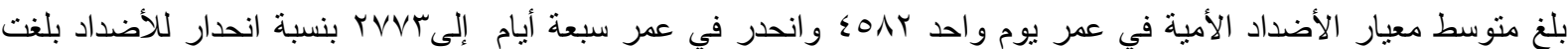

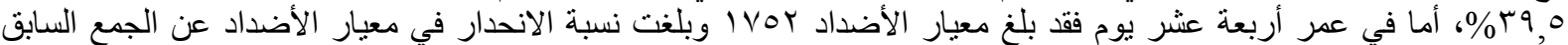

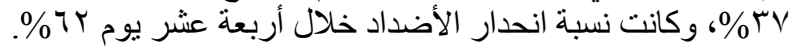
الجدول رقم ب: يظهر قيمة معامل الاختلاف والقيمة صفر ومقدار الانحدار الحاصل خلال ؟ ا يوماً في صبصان المجموعة الرابعة.

\begin{tabular}{|c|c|}
\hline النسبة المئوية & 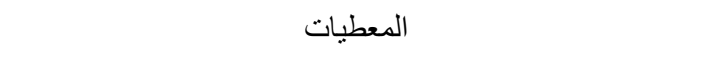 \\
\hline$\% r \leqslant, r$ & معامل الاختلاف في عمر يومCCV\%. \\
\hline$\%$. & النسبة المئوية للعينات التي أعطت قيمة صفراً في عمر يوم واحد. \\
\hline$\% \pi$ & النسبة المئوية لانددار معيار الأضداد خلال ع ايوماً. \\
\hline
\end{tabular}

(1) (الجدول رقم (1)

\section{DISCUSSION}

\section{المناقثة}

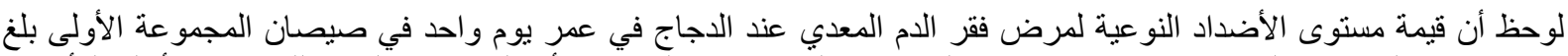

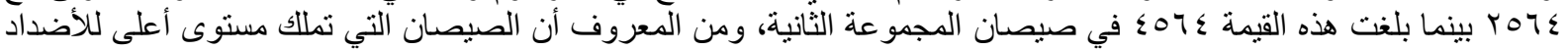
تكون محمية بشكل أفضل ضده المرض.

هذا وقد بلغت قيمة معامل الاختلاف هCV\% في اليوم الأول من عمر صيصان المجموعة الثانية(الناتجة من الأمَّات المحصَّنة)

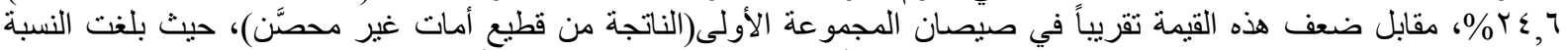

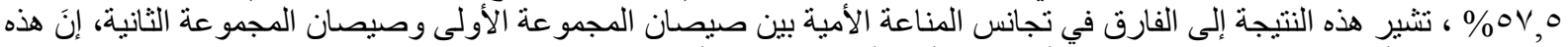

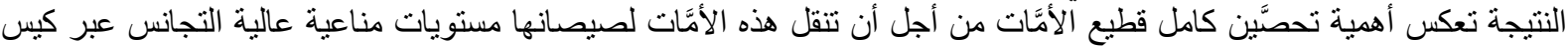
المح، حيث كلما نقصت قيمة معامل الاختلاف كلما كان تجانس المناعة أفضل الفنل.

أثار الباحث كوشكو وزملاؤه (Khoshkhoo et al., 2011) أن هذه النسبة كانت في الصيصان الناتجة من أمَّات غير محصَّنة

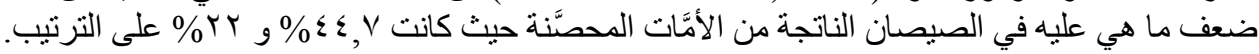


بلغت نسبة العينات التي أعطت قيمة صفر zero titers في اختبار الإليزا في عمر يوم واحد في صيصان المجموعة الثانية (صيصان

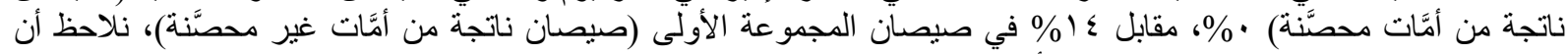

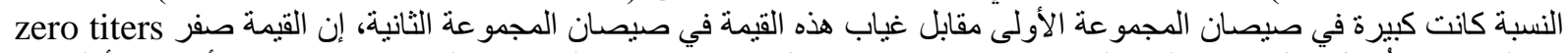

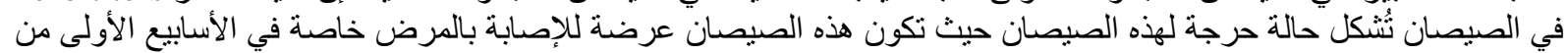

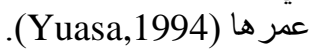

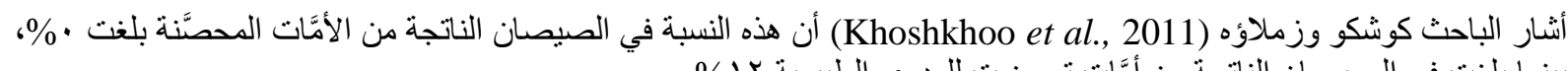

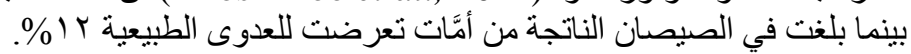

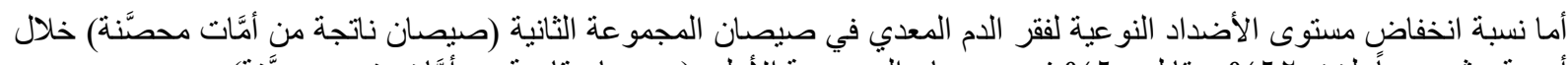

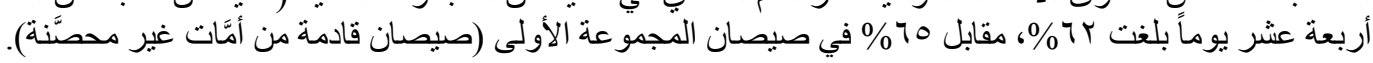

\title{
CONCLUSIONS and RECOMMENDATION
} الاستتتاجات والتوصيات

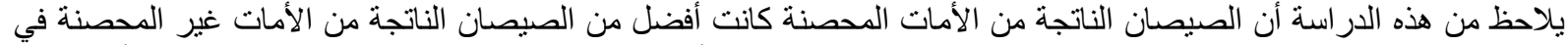

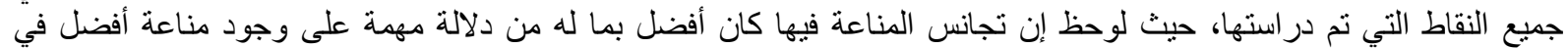

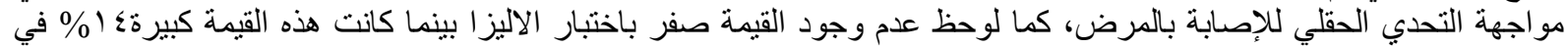

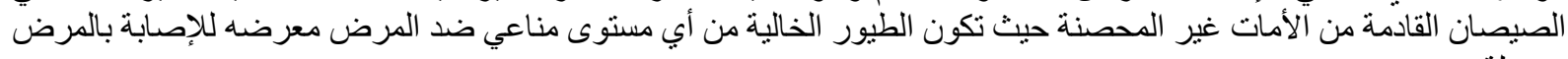
بسهولة.

يستتنج من هذه الدراسة ضرورة الحصول على صبصلان قادمة من أمات محصنة ضد مرض فرض فر الدم المعدي لضمان عدم إصابتها بالمرض و الوصول إلى أفضل النتائج المرجوة في تربية دجاج اللحم.

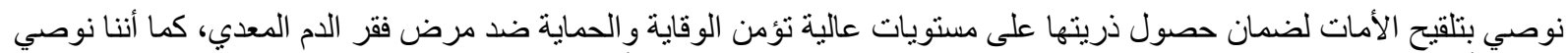

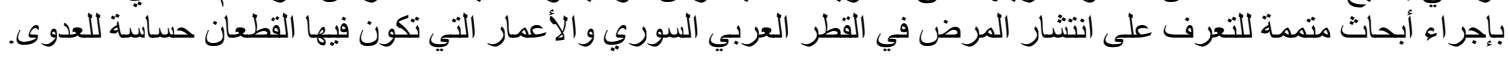

\section{REFERENCES \\ المراجـع}

Chettle, N.J.; R.K.; Eddy, P.J. Wyeth, and S.A. Lister. (1989): An outbreak of disease due to chicken anaemia agent in broiler chickens in England. Vet Rec 124: 211-215.

Engström, B.E. (1999): Prevalence of antibody to chicken anaemia virus (CAV) in Swedish chicken breeding flocks correlated to outbreaks of blue wing disease (BWD) in their progeny. Acta Vet Scand 40: 97-107.

Goryo, M.; Sugimura, H.; Matsumoto, S.; Umemura, T. and Itakura, C. (1985): Isolation of an agent inducing chicken anaemia. Avian Pathol14: 483-496.

Goryo, M.; Suwa, T.; Umemura, T.; Itakura, C. and Yamashiro, S. (1989): Histopathology of chicks inoculated with chicken anaemia agent (MSB1-TK5803 strain). AvianPathol18: 73-89.

Jakowski, R.M.; Fredrickson, T.N.; Chomiak, T.W. and Luginbuhl, R.E. (1970): Hemapoietic destruction in Marek's disease. Avian Dis 14: 374-38.

Khoshkhoo, P.H. Akbariazad, G. and Tashakori, M. (2011): Comparison of CAV antibody titers in a vaccinated and naturally infected broiler breeder flocks. African Journal of Micro Research Vol. 5(20), pp. 3162-3165.

Mankertz, P. (2008): Molecular Biology of Porcine Circoviruses. Animal Viruses: Molecular Biology. Caister Academic Press. ISBN 978-1-904455-22-6. http://www.horizonpress.com/avir

Otaki, Y.; Saito, K.; Tajima, M. and Nomura, Y. (1992): Persistence of maternal antibody to chicken anaemia agent and its effect on the susceptibility of young chickens. AvianPathol21: 147-151.

Pagè-Manté, A.; Saubi, N.; Artigas, C. and Espuña, E. (1997): Experimental evaluation of an inactivated vaccine against chicken anaemia virus. Avian Patho 126: 721-729.

Roussan. D.A. (2006): Serological survey on the prevalence of chicken infectious anemia virus in commercial broiler chicken flocks in Northern Jordan. Int. J. Poult. Sci., 5: 544-546.

Taniguchi, T.; Yuasa, N.; Maeda, M. and Horiuchi, T. (1983): Chronological observations on hematopathological changes in chicks inoculated with chicken anemia agent. NatIInstAnim Health Q (Jpn) 23: 112. 
Yuasa, N. (1983): Propagation and infectivity titration of the Gifu-1 strain of chicken anemia agent in a cell line (MDCCMSB1) derived from Marek's disease lymphoma. NatlInstAnim Health Q (Jpn) 23: 13-20.

Yuasa, N. (1994): Pathology and pathogenesis of chicken anemia virus infection. ProcIntSymp Infect Bursal Dis Chick Infect Anaemia, Rauischholzhausen, Germany, 385-389.

Yuasa, N. and Imai, K. (1986): Pathogenicity and Antigenicity of eleven isolates of chicken anaemia agent (CAA). AvianPa-thol15: 639-645.

Yuasa, N.; Taniguchi, T. and Yoshida, I. (1979): Isolation and some characteristics of an agent inducing anemia in chicks. Avian Dis 23: 366-385.

Yuasa, N.; Noguchi, T.; Furuta, K. and Yoshida, I. (1980): Maternal antibody and its effect on the susceptibility of chicks to chicken anemia agent. Avian Dis 24: 197-201.

Yuasa, N.; Taniguchi, T.; Goda, M.; Shibatani, M. Imada, T. and Hihara, H. (1983a): Isolation of chicken anemia agent with MDCC-MSB1 cells from chickens in the field. NatlInst Anim Health Q (Jpn) 23:7577.

Yuasa, N.; Taniguchi, T.; Imada, T. and Hihara, H. (1983b): Distribution of chicken anemia agent (CAA) and detection of neutralizing antibody in chicks experimentally inoculated with CAA. NatlInst Anim Health Q (Jpn) 23: 78-81. 